\title{
Urban Instrumentality: Pedagogy in an Era of Ecological Design Challenges
}

\author{
JOSE L.S. GAMEZ \\ University of North Carolina Charlotte
}

In 2014, NASA projected higher than previously predicted irreversible climate changes that will result in sea levels rising 1 to 2 meters worldwide by 2100 . Along the way, according to the Lon-don School of Economics' Urban Age Project, the global population will become $75 \%$ urbanized by 2050; much of this urbanization is occurring in developing countries, which will account for approximately 4 out of every 5 city dwellers - often in coastal locations. This combination of rapid urbanization and environmental change requires a reinterpretation of development, architecture, and ecology in which an integration of urban components is essential if the management of the envi-ronment and resources is to result in resilient and livable cities. With this in mind, this paper re-flects upon two three-year collaborations between our Master of Urban Design program and uni-versities in parts of the world that are undergoing the brunt of this global urbanization: China and Brazil. Through a discussion of a series of summer workshops, fundamental challenges to the inte-gration of ecological strategies into design pedagogies are illustrated through the experiences of students.

\section{INTRODUCTION}

In 2014, NASA projected higher than previously predicted irreversible climate changes that will result in sea levels rising 1 to 2 meters worldwide by $2100 .{ }^{1}$ Along the way, according to the London School of Economics' Urban Age Project, the global population will become $75 \%$ urbanized by 2050 ; much of this urbanization is occurring in developing countries, which will account for approximately 4 out of every 5 city dwellers - often in coastal locations. ${ }^{2}$ These transformations influenced the planning and implementation of our Master of Urban Design Program in the School of Architecture (SoA) at UNC Charlotte in 2008 and, later, its required international experience-the summer capstone studio abroad, which enabled our program to located itself in places in which urbanization and sustainable development questions could be examined first hand.

This combination of rapid urbanization and environmental change requires a reinterpretation of development, architecture, and ecology in which an integration of urban components is essential if the management of the environment and resources is to result in resilient and livable cities. This translated into our pedagogical approach that attempts to bring questions of urbanization and climate change into the curriculum. In a sense, impending global crises demand a global pedagogy. With this in mind, this paper reflects upon two collaborations between our Master of Urban Design program and universities in parts of the world that are undergoing the brunt of this global urbanization: China and Brazil. ${ }^{3}$ We began our quest to explore global sustainable development strategies 2013 in China with a 3-year research cycle; this was followed by a 3-year partnership in Brazil that began in $2015 .{ }^{4}$ In many ways, these programs were designed to provide opportunities for our students to engage a range of topics not often studied in western design programs precisely because the most rapidly transforming urban contexts facing the profession often lie outside the United States. Framed by themes of verticality and compactness, complexity and density, and sustainable development, the program focused upon emerging patterns of Chinese centralized planning and urbanization as our first set of case studies. These studies were followed by a series set in Brazil where urbanization is often poorly controlled and often informally driven.

Our international urban studies were also a part of a larger initiative in the SoA aimed at integrating global studies and to help our students understand their roles in an increasingly urbanized and resource challenged environment. ${ }^{5}$ I mention this because it sets the stage for the challenges that we faced as students participated in intensive workshops with partnering institutions in which city-building skills and sustainable development strategies were tested and, thus, expanded our academic and professional discourses. Our view, like that of many others, was (and still is) that our curriculum must integrate environmental and sustainable development strategies into a holistic approach to education. ${ }^{6}$ What follows, is a discussion of our summer workshops that illustrate fundamental challenges that emerged as we attempted to integrate ecological issues into design pedagogies. Using cities like Suzhou and Rio de Janeiro as laboratories, students explored the design, ecological, and socio-cultural dimensions of building resilient cities and their experiences in attempting to address the relationships between density, social vitality and cultural perceptions suggest a that a combinatory approach to urban forms may provide a way forward.

CHASING CHINA (2012-15) \& READING RIO (2015-17)

Our program in China focused upon emerging patterns in urbanization by addressing questions of scale, density, centralized planning, and sustainable development through exposure to the complexity of cities like Suzhou and through work with students from Suzhou University of Science and Technology, Xiamen University, and Wuhan University. ${ }^{7}$ By the time of our 
first visit, the country had undergone intensive urbanization for nearly two decades and it seemed as if the city building theories that we were discussing in Charlotte were being built in China. Our overall program was framed through the lens of "Vertical Urbanism" and addressed visions of sustainable development in the form of highly compact urban places. Urbanism in China at the time was marked by high density, high rise living and included complex commercial, recreational and social programming uncommon in the west. Verticality, in this sense, provided a paradigm that shaped new urban centers, distinguished them from traditional downtowns, and blurred distinctions between the local and the global while maintaining Chinese imprints. What our students witnessed what the political economist Bob Jessop has called "glubanization"-global processes that impact cities differently while simultaneously creating many similar attributes rooted in competitive place-based dynamics. ${ }^{8}$ This high density urbanization had clear consequences; for example, hazardous air quality plagues many mega-cities in China and contributes to acid rain in many villages on their outskirts. ${ }^{9}$

As a coastal metropolis, Rio is characterized by natural water systems that, due to poorly managed development, contribute to flooding and mudslides. Yet, growth continues in ecologically sensitive areas and this situation has been exacerbated by recent mega-event driven development coupled with inter-dependent informal urbanization. In Zona Oeste and Barra da Tijuca, or the western zone of Rio de Janeiro, these came in the form of the 2016 Summer Olympics, the 2014 World Cup, and the 2007 Pan American Games. These large scale planned initiatives drew workers who built adjacent favelas alongside the construction sites of these global events. This contrast between the highly formalized alongside an equally impactful local informalization is related to the glurbanization we saw in China and it framed student questions about the fragile ecology of Zona Oeste. These forces made Zona Oeste a compelling area for design investigation tied to climate change and, in particular, sea level rise precisely due to its coastal location. Working alongside students from the Pontifical Catholic University at Rio de Janeiro's Urbanism Laboratory within the Graduate Program of Architecture of the Architecture and Urbanism Department, our students explored the existing fabrics of the city (built and ecological) in order to identify unique characteristics to drive design integration later.

\section{THE WORKSHOPS}

Each MUD international program was framed as a 3-year research cycle and within a specific region of investigation. ${ }^{10}$ This format enabled an evolving yet structured teaching environment and it also allowed faculty and students to investigate urban design questions in an iterative fashion. The continuity of exploration also allowed our faculty to sustain collaborations with local faculty and contacts over time. For our MUD program, this has led to studio publications that feature the work of the students and scholarly monographs that feature the work of faculty from collaborating institutions. ${ }^{11}$

Design teams for the workshops were composed of students and faculty from each participating university and each also engaged from local professionals from a range of industries and organizations. Typically, teams would consisted of 4 or 5 students -2 or 3 from Charlotte and 2 or more from our Chinese or Brazilian hosts. In China, the teams were made up of architecture and urban design students. In Brazil, the disciplines were more diverse; in order to enrich the experience of the UNC Charlotte students, we cross-listed our coursework with Latin American Studies. Additionally, our collaborating partners at PUC-Rio opened the workshops to their sustainable urbanism program broadly so the mix of local students ranged from architecture to urbanism to environmental sciences and biology. Given the topic of sea level rise that helped frame the program in Rio, the added depth provided by nondesign students proved to be particularly valuable. While the results of each three year cycle produced substantial design and pedagogical research, each individual workshop contributed significant insights. The outcomes typically came in the form of four or five group projects presented at a final review with jurors from local universities, client/developers, and municipal organizations as well as local design firms.

\section{CULTURE, CLIMATE \& PEDAGOGICAL CHALLENGES}

In China and Brazil, development itself is a significant ecological challenge and its sheer scale often overwhelmed our students. Scale and verticality in Chinese cities became traits that our students attempted to address while more complex ecological challenges remained symbolically important but typically poorly resolved. In Brazil, the landscape (both cultural and geographic) challenged the abilities of students to see beyond impending climatic changes. In many cases, our students could not comprehend why development had been allowed to continue in areas that will be severely impacted by sea level rise. In both cases, our pedagogical challenges were tied to differing cultural understandings of density, scale, development pressures, or of the role of the public sector in protecting environmentally sensitive areas.

Given China's centrally controlled planning, our students assumed a level of accountability that was not manifested most places. Air quality alone was an indicator that growth and sustainability were not equally balanced in the country's plans to urbanize. For example, our collaborations with the College of Architecture and Planning at Suzhou University of Science \& Technology focused on a former industrial site in the Suzhou Industrial Park (SIP), which had been redeveloped in 1994 as a joint venture between the Chinese and the Singaporean governments. The SIP served as a high-profile demonstration project featuring Singapore's economic development models translated to mainland China. Envisioned as 
Suzhou's business center complementing its historic downtown, SIP developed into a city of over 700,000 residents. Nevertheless, after many years of rapid growth, the widely lauded model faced challenges as the city underwent economic and social transformations in which high-end sector service industries rose to importance. By the time of our visits, SIP was a post-industrial landscape in which poorly constructed buildings showed signs of deterioration (despite having been constructed between 2002 and 2004) and the streetscape was in poor condition, canals were overgrown and littered with waste, and the local air and water quality were poor. In addition, the site's land use planning did not match the proposed vision of a high density, mixed use and transit-oriented development.

In Rio, the country's inability to control growth gave rise to different issues and environmental consequences. Unfortunately, Barra da Tijuca itself is not well suited to development. Due to a high-water table, the soft coastal basin soils, and sensitive ecological systems, it is easy to understand why the larger area is a poor candidate for development. The ground is so unstable, for example, that contractors must raise the level of sites by 2 meters; soils are imported and compacted to prevent future sinking. Then, each site sits vacant for two years so soils settle before construction can occur. Additionally, Barra da Tijuca lies within the larger Jacarepaquá Basin, a "double barrier system" watershed bounded by the Atlantic Ocean, lagoons, marshes, and mountains. ${ }^{12}$ This kind of geographical area is particularly susceptible to sea level rise given its geological formation and coastal location. ${ }^{13}$ Interestingly, the shadow of Brazilian Modernism can still be felt here. By the 1960s, Zona Oeste became a focus for national interests and, with the introduction of the Lagoa-Barra Highway, the area became a more accessible from Rio's famous Zona Sul (where Copacabana can be found). Zona Oeste was imagined as a new regional center for the city; economic development and a new regional metropolitan center in Barra da Tijuca were so important that the country's most prominent architect and planner, Lucio Costa, was commissioned to create a vision for the area in 1969-one that would result in the world's most beautiful "cidade oceanica," or ocean-side city. ${ }^{14}$ However, development and governmental pressures allowed growth to all but erase Costa's framework. Development has resulted in residential towers serving as vertical cul de sacs complete with active security personnel, gates, and fences.

\section{DENSITY AND DISBELIEF}

In both Brazil and China, our students struggled to address environmental challenges while also coming to terms with the seemingly unprecedented density that they encountered. Given the rate of Suzhou's expansion, our design teams sought to address high-density urbanism through ecological repair and verticality. They realized quickly that perceptions of density, complexity, mixes of uses, and of spatial organizations (such as commercial or semi-public uses below and above the ground plane) were conditioned by local cultures and practices. Mixed use, for example, in much of the United States is often not nearly as mixed as what we experienced in Chinese metropolitan centers. Similarly, the idea that a new development may house 100,000 people or more surprised our students but is common practice China. This is fostered by a national "urban administrative hierarchy" that often concentrates development in specific cities that includes combinations of infrastructure, intensive mixed use developments, housing for hundreds of thousands, and commercial, cultural and entertainment facilities..$^{15}$ In Rio, our design teams contended with a set of environmental conditions that raised questions rooted in disbelief ("why would anyone build there?"). These questions stemmed from the premise underpinning our Brazilian partnership; we set a planning horizon of the year 2100 by which time sea levels are expected to rise by 1 to 2 meters worldwide. Climate change has already contributed to the growing frequency of torrential rainfall in Latin America and, as cities like Rio have matured, impermeable surfaces have also increased and water management issues became more challenging. ${ }^{16}$

The intersection of human-made and natural systems were common to both Suzhou and Rio but they were manifested in different ways. One aspect of growth that our students experienced was an "expanded urban scale" that has been "stretched... and upgraded as an integral part of the strategy of place-marketing and place-promotion in order to capture and fix global mobile capital." ${ }^{17}$ This combination of placebased development and expanded urban scale presented significant challenges for our students in China:

Student 1 (2012 in China): The most challenging aspect was to reconcile our desire to apply western design principles to China's auto-oriented mega-block development. Another challenge was conceptualizing how vertical mixed use buildings would accommodate the current and predicted population density in China. Ultimately, we decided to hold firm and to design smaller more pedestrian-friendly blocks. We learned quickly to think at much larger densities than we were used to designing for in the west.

Student 2 (2014 in China): Scale was a bit overwhelming and we were shown two polemics in China: the mega block and the small winding, organic town structure. So, even though we have an arsenak if Western design techniques, I think that all went out the window when we were introduced to the site.

In Rio, scale remained a challenge but students also fell prey to a fear of the impending sea level rise: 
Student 3 (2017 in Rio): The challenge was to think of a sustainable and humanitarian way to deal with the global issue of climate change and sea level rise. Walkability and accessibility as known in North America are as challenging to implement in Latin America as in North America as they both are subjected to large urban developments that do not take into consideration human scale.

Student 4 (2016 in Rio): The biggest challenge (was) that our group didn't believed that the site was suitable for development. Even though we had an assignment to develop the area, we decided that we would plan out and in 100 years the development would turn into ruins and be part of the landscape, protecting the wildlife habitat.

When faced with these challenges, students quickly returned to basic skills that they had learned before traveling and attempted to stretch them to fit new circumstances. Interestingly, in their efforts to reconcile the contrasts between their design experiences and the contexts that China and Brazil presented, students explored design frameworks rooted in combinatory and ecological urbanisms. ${ }^{18}$ Given the need to act, the ideological divide between city building strategies so often seen in academia was quickly disappeared; New Urbanism no longer sat apart from Landscape Urbanism, for example. Students borrowed strategies from one camp to augment those in another: pedestrian scaled increments were layered over mega-blocks and infused with ecological forms; compact development models were infused by vertical high-rise mixed-use; ecological systems stitched together buildings, landform and public spaces in three-dimensional and multi-programmed frameworks.

\section{THOUGHTS ON THE NEED FOR A COMBINED URBAN ETHOS}

Upon reflection on 6 years of internationally programming, it is clear that unique opportunities exist to prepare students for success in a global profession. These opportunities highlight global issues and their impacts upon local conditions; in this sense, the need to redefine the roles of infrastructure, design and ecology, for example, can be placed in stark relief through first hand explorations. Given the complexity of the issues that face cities in the 21st century, workshops such as ours in China and Brazil, are crucial resources that can anchor international networks of experts, place global research partnerships in positions to influence local actions, and support international outreach projects.

As is often the case with university/community collaborations, clients and city representatives in both Suzhou and Rio were impressed with the insights offered by students and with the applicability of many of their ideas to the development projects in question. Some ideas, such as flooded landscapes or large scale water-related infrastructure investments, may have seemed beyond the realm of financial or political feasibility, but the rich urban analyses embodied in the projects was often convincing and thought-provoking particularly with regard to a wider urban context. By engaging our student teams as "outsiders" in the conversation, voices could be raised that underscored important issues facing not only the long-term development of each specific site but also issues shaping the urban futures of each host city. This kind of global engagement with sustainable development issues represents a necessary role for urban designers in particular: that they must become managers who can translate and direct (if not deploy) the cultural, scientific, and often technical expertise of other disciplines in the service of cities far removed from but none the less interconnected with their home institutions. ${ }^{19}$

The composition and format of each team both reflected this approach while also challenging us (faculty and students) to think beyond the "rules of thumb" that we have come to rely upon in the U.S. The interconnection between students from several parts of the world working collaboratively quickly helped highlight cultural dimensions and limitations of design strategies rooted in the differing educational and lived experiences of each student.$^{20}$ For example, our program enrolls both domestic and international students who, in the case of PUC-Rio for example, meet with not only Brazilian but also French, African, and other Latin American students. In this sense, each team represented a set of global cultures who often negotiated working definitions of basic design terms such as density and scale. Additionally, our workshops fostered collaborative investigation and design exploration, which often differs from many architectural design studio formats. For many students involved, this format necessitated a departure from a design culture that privileges individual competition in favor of sharing of expertise, local and global knowledges, and it opened interesting opportunities for interpretation and speculation. Diversity, in this setting, was an asset that enabled cooperation as well as cultural and professional growth: "in this context, it is precisely how morally appropriate knowledge is constituted and the relations of power at stake in doing so" become integral to the overall learning environment. ${ }^{21}$

The interactions between our students and those in China and Brazil led to an expanded sense of the compact city, one that builds upon differing cultural perceptions of scale, complexity, density, and sustainability. For both our Brazilian and Charlotte-based students, for example, this points to a need to examine what Viniece Jennings, Jessica Yun and Lincoln Larson have described as "values and valuation," or cultural perceptions tied to professional "duties and obligations within the human-nature relationship." 22 While their work focuses upon environmental ethics with respect to health and wellness, the basic argument that Jennings et al make is generalizable to urban design education. In other words, urban design education can reinforce both cultural 
awareness as well as environmental ethics as we "continually confront decisions about what we value and what others value, how we are required to act, and how we feel about ourselves when we do."

Despite the challenges that our students faced while abroad, our basic pedagogical interest in complex and sustainable forms of development remain important aspects of our program. In fact, the global contexts that we study shed light upon how our practices in the U.S. and urban circumstances found elsewhere can interact. Urban design, like its allied design disciplines, requires ecological sensitivity and critical cultural thinking. In the case of our work, we find that our cultural perceptions, as well as those of our students, have shaped our notions of good urban design in productive but limited ways. While this does not negate their value, it certainly points out that our values are not universal. This is not earth shattering news but it suggests the need for urban designers to deploy their imaginations as critical cultural practice.

\section{ENDNOTES}

1. Peter Hogarth, 2014. "Preliminary Analysis of Acceleration of Sea Level Rise the Through 20th Century using Extended Tide Gauge Data Sets," in Journal of the Through 20th Century using Extended Tide Gauge
Geophysical Research: Oceans 119 (August) 7645-7659.

2. Barbara Neumann, et al., 2015. Future Coastal Population Growth and Exposure to Sea-Level Rise and Coastal Flooding - A Global assessment. PLoS

3. In China, students were led by Dr. Zhongjie Lin who introduced them to a context in which contemporary urban design theories were being tested in real time and at enormous scales. In Brazil, Dr. José Gámez led students throug major event-driven infrastructural investments.

4. One result of these research partnerships has been the publication of academic and student work; an edited monograph is under way documenting our work in Rio while the work from China has already been published [see: Zhongjie Lin and José L.S. Gámez, editors, 2018 Vertical Urbanism: Designing Compact Cities in China (London: Routledge).

5. For an overview of the School of Architecture's approach to international programming, see: Chris Jarrett and Zhongjie Lin, 2014. "Incremental Initiatives: Global Programming X6" in Globalizing Architecture: Flows and Disruption Proceedings of the 102nd Annual Meeting of the Association of Collegiate Schools of Architecture. Edited by John Stuart and Mabel Wilson. (Washington DC: ACSA Press) 597-603.

6. Many authors have pointed out that education generally must aim to instill an ethos of sustainability among students of all ages in order for human-kind to address questions of sustainability and sustaiable development; for example see: Michael Brody,1995. "Development of a Curriculum Framework for Water Education for Educators, Scientists, and Resource Managers" in the
Journal of Environmental Education, 26:4, 18-29; see also: Evelyn Martin and Journal of Environmental Education, 26:4, 18-29; see also: Evelyn Martin and in Planning Education" in the Journal of Planning Education and Research (12) 117-126.

7. The full portfolio of projects can be found online in a companion publication to Vertical Urbanism titled Vertical Urbanism: Case Studies in Chinese Urbanization: https://issuu.com/unccmud/docs/vertical_urbanism_portfolio-s

8. See: Bob Jessop and Ngai-Ling Sum, 2000. "An Entrepreneurial City in Action: Hong Kong's Emerging Strategies in and for (Inter)Urban Competition" in

9. Chak K. Chan and Xiaohong Yao, 2008. "Air Pollution in Mega Cities in China" in Atmospheric Environment 42: 1- 42.

10. The MUD summer semesters start in May and ends in August and is made up of two, full-time five-week sessions. The first session takes place overseas, and consists of an intensive advanced urban design studio and urban seminar 6 credits total); given the combined curricular and travel demands of a session abroad, these two courses are essentially merged to provide an intensive and immersive workshop that blends both lecture, site visits, research and studio environments. While the workshops have been typically based in one location, other activities are woven in that augment the design experience: travel, visits to urban design firms and important sites, as well as guest lectures, symposia, and exhibitions. This is followed by second session that returns to Charlotte to focus on design development.

11. See: Zhongjie Lin and Jose Gamez. Vertical Urbanism: Designing Compact Cities in China (New York: Routledge, 2018); Jose Gamez, Zhongjie Lin and Jeffery Nesbit, Cidade Oceanica: Environment and Urbanisation in Rio (forthcoming Routledge 2019)

12. Gilberto T. M. Dias and Björn Kjerfve, 2009. "Barrier and Beach Ridge Systems of the Rio de Janeiro Coast" in Geology and Geomorphology of Holocene Coastal Barriers of Brazil. Edited by Sérgio R. Dillenburg and Patrick A. Hesp. (Verlag: Springer) 242.

13. Dieter Muehe, 2010. "Brazilian Coastal Vulnerability to Climate Change," Pan-American Journal of Aquatic Sciences, 5 (2) 173-83.

14. Lucio Costa, 1969. "Plano-Piloto para a Urbanizacao da Baixada Compreendida Entre a Barra da Tijuca, o Pontal de Sernambetiba e Jacarepagua" in Arquitextos (Rio de Janeiro: Prefeitura da Cidade).

15. Wei Houkai, 2015. "The Administrative Hierarchy and Growth of Urban Scale in China," in the Chinese Journal of Urban and Environmental Studies, 3 (1): 1550001-5.

16. Fernando Lara, 2010. "One Katrina Every Year: The Challenge of Flooding in Tropical Cities." in 98th ACSA Annual Meeting Proceedings: Rebuilding (Washington D.C.: Association of Collegiate Schools of Architecture) 221-226.

17. George C. S. Lin, 2007. "Chinese Urbanism in Question: State, Society, and the Reproduction of Urban Spaces" in Urban Geography, 28 (1): 24.

18. For example, students were asked to read Thom Mayne's book Combinatory Urbanism: The Complex Behavior of Collective Form (Los Angeles: Stray Dog Café, 2011); students were also encouraged to examine the work of leading "landscape urbanists" such as Stan Allen and James Corner as well as innovative interdisciplinary design firms such as Susannah C. Drake's DLANDstudio
that integrate (among other things) ecological strategies into their work.

19. Dana Cuff. Architecture: The Story of Practice (Cambridge: MIT Press, 1991) 248-63.

20. Interestingly, each student team represented multiple countries and cultures: our urban design program regularly enrolls students from China, the Midde East, and India who come to the U.S. to study abroad, our program then takes these international students to yet another country in which, in the French, African, and other Latin American students. In this sense, each tean French, African, and other Lath Ame who often negotiated working definition of basic design terms such as density and scale.

C. Greig Crysler, Critical Pedagogy and Architectural Architectural Education, May 1995, 48 (4) 214.

22. See: Viniece Jennings, Jessica Yun and Lincoln Larson, 2016. "Finding Common Ground. Envin healthcare4030061.

23. Elizabeth Boling and Richard A. Schwier, 2017. "Curators' Notes" in Studio Teaching in Higher Education: Selected Case Studies (New York, Routledge) 19.

24. I am borrowing (and, perhaps, distorting) Arjun Appadurai's work on the imagination in contemporary global cultural production; see: Arjun Appadurai, 1998. Modernity at Large: Cultural Dimensions of Globalization (Minneapolis: University of Minnesota Press). 